\title{
Exploring the Interplay of the Design and Emergence of Business Processes as Organizational Routines
}

Business process management is often considered as a top-down management activity. This view is inconsistent with the observation that information infrastructures are at drift, outside top-down management control. To reconcile both views, a meta-framework is presented that frames the interplay of the design and emergence of business processes. Business processes are identified as a particular form of organizational routines. This observation opens up a rich body of knowledge for theorizing on business processes. The design of IT artifacts is conceptualized as an engineering activity as well as a process of social construction. Emergence refers to a mutually constitutive duality of social structure and human agency.

\section{The Author \\ PD Dr. Daniel Beverungen ( $\varangle$ ) \\ European Research Center for \\ Information Systems \\ University of Muenster \\ Leonardo-Campus 3 \\ 48149 Münster \\ Germany \\ Daniel.Beverungen@ \\ ercis.uni-muenster.de \\ Received: 2014-01-14 \\ Accepted: 2014-03-27 \\ Accepted after one revision by \\ Prof. Dr. Martin Bichler. \\ Published online: 2014-06-24}

The current paper is a further development of Beverungen D (2013) On the design of IT artifacts and the emergence of business processes as organizational routines. In: 34 th International conference on information systems, Milan, Italy.

This article is also available in German in print and via http://www. wirtschaftsinformatik.de: Beverungen D (2014) Über das Zusammenwirken der Gestaltung und Emergenz von Geschäftsprozessen als Organisationsroutinen. WIRTSCHAFTSINFORMATIK. doi: 10.1007/s11576-0140425-3.

(C) Springer Fachmedien Wiesbaden 2014

\section{Introduction}

Business Process Management (BPM) has been conceptualized as a cross-border research field that consolidates previous work on "how to best manage the (re-) design of individual business processes and how to develop a foundational Business Process Management capability in organizations catering for a variety of purposes and contexts" (vom Brocke and Rosemann 2010c, p. viii). Given its long research tradition, it is surprising that BPM thought leaders recognize a lack of theory in this field. Melão and Pidd (2000, p. 111) argue that "there are few significant attempts to develop theoretical positions on possible approaches to BPM, possibly because the development of BPM has been driven by practitioners rather than by academics."

Melão and Pidd (2000) find that much of the work in the BPM field tends to assume implicitly that business processes are deterministic machines that can be purposefully designed and implemented in the organization in a top-down process. However, this view contradicts Ciborra and Hanseth's (1995) observation that information infrastructures are at drift, a term that refers to the lack of top-down management control. Therefore, BPM literature needs to theorize about the workings behind this drift and about its interplay with top-down engineering processes in order to understand the prospects and limitations of 'design' itself.
A conceptual research approach is taken in this paper to develop a metaframework that explains the interplay of the design and emergence of business processes as organizational routines. Conceptual research is a non-empirical research method (Mora et al. 2008) for developing theory, based on reflexion on existing theoretical concepts. Even if few attempts have been made to classify different conceptual research methods (Meredith 1993), Mora et al. (2008) demonstrate that conceptual research is one of the most frequently used methods in IS research. They refer to conceptual studies (as designing a new conceptual artifact: a construct, a framework/model, a method/process or a system/component) and scholastic studies, reviews, tutorials and normative writing (Mora et al. 2008). Meta-frameworks are a conceptual method for building theory based on the integration of previous frameworks, "while avoiding composite variables and clearly defining the boundaries of the theory" (Meredith 1993, p. 10).

The proposed meta-framework is built on two streams of research that have remained largely neglected in the BPM field. The first strand of work focuses on organizational routines, conceptualized as "generative systems that produce repetitive, recognizable patterns of interdependent action carried out by multiple participants" (Pentland and Feldman 2008, p. 236). The second strand of literature views structure and agency as a mutually constitutive duality, based 
on structuration theory (Giddens 1984) and its IS successor theories (Jones and Karsten 2008), including adaptive structuration theory (DeSanctis and Poole 1994) and the practice lens account (Orlikowski 2000). The resulting metaframework builds on the work of Pentland and Feldman (2008), the design principles for organizational routines proposed by Becker et al. (2013), and principles of the social construction of technology (Lyytinen et al. 2008).

The meta-framework contributes to explaining the interplay of the design of IT artifacts and the emergence of business processes as organizational routines. Two major theoretical insights into business processes are gained. First, drift signifies that developers and managers cannot base the design of IT artifacts for business processes solely on a mechanistic engineering rationale, but must ensure that the design is subject to a process of social design shaped by processes of sense-making and negotiation. Second, while IT artifacts enable and constrain business processes, business processes emerge as social structures based on the actions of the users who perform their day-to-day work, thereby both intentionally and unintentionally re-constructing the company as a social institution. From a designer's point of view, the troubling consequence is that business processes can only be incompletely shaped by IT artifacts such as business process models and enterprise resource planning (ERP) systems. The purpose of the paper is not to criticize top-down design processes per se, but to arrive at a more realistic appraisal of the prospects and constraints of design itself.

The remainder of this paper is structured as follows. Section 2 reviews the theoretical backgrounds of BPM research, organizational routines, and structuration theory. Section 3 presents related work of the BPM community and documents to what degree the proposed theoretical view extends previous thinking. Section 4 presents the resulting meta-framework, and Sect. 5 reflects the theoretical and managerial contributions the paper offers. Section 6 provides a research outlook.

\section{Theoretical Foundations}

In the following, theoretical foundations from three strands of literature are presented. First, views on business processes as deterministic machines and business processes at drift are contrasted to outline different assumptions on the manageability of business processes. Second, foundational properties of structuration theory are presented to conceptualize drift. Third, properties of organizational routines, a concept discussed in organization science, are summarized. Literature on organizational routines has been related to structuration theory before and also parallels some of the central concepts in BPM literature.

\subsection{Business Processes as Deterministic Machines}

Extending a first definition of processes "as essentially any sequence of work activities," the business process reengineering school conceptualizes a business process as "end-to-end work across an enterprise that creates customer value" (Hammer 2010, p. 4). BPM is a boundaryspanning research field that focuses on organization's foundational capabilities to manage their business processes (vom Brocke and Rosemann 2010c). Harmon (2010) traces the antecedents of the BPM field back to three research traditions: the management tradition of BPM research, which focuses on overall firm performance and the strategic alignment of business processes to organizational objectives; the quality or worksimplification tradition, which strives to improve the quality of business processes, traditionally in the production of physical goods; and the IT tradition, which uses computers and software applications to automate work processes.

These traditions tend to view business processes as implemented in a topdown process that is aligned with business strategy, quality goals, or functional decomposition based on IT. The business process reengineering approach as conceptualized by Hammer (2010) is based on creating a concept of a business process that is supposed to be instantiated and executed by the people in an organization. Deviations from the engineered blueprint are perceived as 'faults' caused by inadequate training, insufficient resources, or faulty equipment that must be traced in root cause analyses and corrected by adapting the design of the conceptual business process. The vision behind this approach is to create "high-performance processes, which operate with much lower costs, faster speeds, greater accuracy, reduced assets, and enhanced flexibility" (Hammer 2010, p. 7). Kawalek, who early recognized the interdependencies of BPM and classic organizational literature, finds that an effective implementation of business process reengineering (BPR) concepts "is essentially top-down", since it requires substantial investment decisions that "come from the top of the organization structure downwards" (Kawalek 1994, p. 278, 277).

These contributions illustrate a perception of business processes as deterministic machines which seems often to be taken for granted in designoriented contributions to the BPM field. In this metaphor, a business process "is a fixed sequence of well-defined activities or tasks performed by 'human machines' that convert inputs into outputs in order to accomplish clear objectives" (Melão and Pidd 2000, p. 112), consistent with Morgan's (1997) metaphor of a bureaucratic machine.

\subsection{Business Processes at Drift}

Traditional management literature conceptualizes management control as an orderly, organized, top-down process, which is a fundamental principle of positivist thinking (Ciborra and Hanseth 1995). This view puts the centrality of measure and control center stage while defining technology "as a powerful set of tools augmenting human action and thinking" in a quest to "pull the messy everyday world towards an almost geometrical or mechanical view of the business organization" (Ciborra and Hanseth 1995, p. 5). In light of the arguments in the preceding section, much of the BPM literature is no exception in this regard. Ciborra criticizes this view of structured information systems methodologies in an article on strategic alignment:

"[In this view] systems are objects, knowledge is data, work is business process, and people are emotionless decision makers who have to align their preferences and adjust to the changes rationally planned for them. It is the "de-worlded" world of business engineering models, where designers, consultants, and managers juggle around boxes and arrows to come up with solutions that optimize pre-selected performance criteria." (Ciborra 1997, p. 75)

Contrasting this view, Ciborra and Hanseth (1995) highlight that information infrastructures, including the business process infrastructure, are at drift, 
rendering top-down management control of companies inoperable. Thus, in Ciborra and Hanseth's (1995, p. 5) view, "alignment is a long, tortuous, and fragile process whereby multiple actors and resources try to influence each other to constitute a new socio-technical order." Therefore, the attempt to change infrastructures, including an organization's business process infrastructure, is subject to resistance, deals, side effects, and the properties of the IT landscape. Others researchers have traced the unfeasibility of top-down control back to user resistance, including workarounds (Ignatiadis and Nandhakumar 2009), deliberate errors committed by users (Ferneley and Sobreperez 2006), passive resistance misuse and sabotage (Marakas and Hornik 1996), status quo bias (Kim and Kankanhalli 2009), IS avoidance (Kane and Labianca 2011), and cynicism (Selander and Henfridsson 2012), as discussed by Bagayogo et al. (2013).

It follows that infrastructure is partially outside management control and tends to drift, that is, an infrastructure deviates from its planned purpose for a variety of reasons outside people's influence, resulting in a perceived need for more control (Ciborra and Hanseth 1995).

\subsection{Social Structure and Agency as a Mutually Constitutive Duality}

Business processes are social structures that are constructed and re-constructed by their performance in the day-today business of organizations. Therefore, structuration theory and its IS successor theories provide a theoretical lens which allows for insights into the constitution of business process infrastructures that are subject to drift. An early claim for interpreting BPR activities from the point of view of organizational theories, such as structuration theory, was made by Kawalek (1994). However, this idea has apparently not been developed further in sufficient depth, as we shall see in the literature review reported below.

\subsubsection{The Duality of (Social) Structure(s)}

Structuration theory (Giddens 1984) conceptualizes social structure and human agency as a mutually constitutive duality while shedding the domination of structure over action that is often assumed in functionalism and naturalism as well as the domination of action over structure which is often assumed in hermeneutics and humanism. Although the "central concern of structuration theory is the relationship between individuals and society" (Jones and Karsten 2008, p. 129), Jones and Karsten (2008) identify a rich array of applications of structuration theory in IS research that have made it one of the most frequently used seminal theories in IS research.

Structuration theory conceptualizes structure as "continuously produced and reproduced through situated practice" (Jones and Karsten 2008, p. 128). The "duality of structure" proposes that the "rules and resources drawn upon in the production and reproduction of social action are at the same time the means of system reproduction" (Giddens 1984, p. 19). In other words, structure always both constrains and enables human agents' actions, while structure itself is produced and re-produced only through human action (Giddens 1984, p. 25). It follows that from the point of view of structuration theory, structure cannot be 'inscribed' or 'embedded' into technology (Jones and Karsten 2008).

\subsubsection{Power, Agency, and Emergence}

Because of the reproduction of structure by actions, the assumption that individuals have the ability to transform social structures (Jones and Karsten 2008) is a central tenet of structuration theory. Giddens (1984, pp. 5-14) posits that all humans are knowledgeable agents who can describe what they do and rationalize their actions. Power is conceived as the most central elemental concept in the social sciences since it is "the means of getting things done and, as such, directly implied in human action" (Giddens 1984, p. 283). Actors' power over resources enables actors to choose how they act, including complying with or changing social structure, resulting in a reproduction of social structure. Thus, human agents always have the power to "act otherwise" (Giddens 1984, p. 14).

Human intentionality denotes that the activities of human beings often follow plans and goals, even if these plans and goals cannot be explicitly formulated or humans are unaware of or unable to recognize their motivations (Jones and Karsten 2008; Nandhakumar et al. 2005). While "agency refers to doing" (Giddens 1984 , p. 10), actions can have intended consequences as well as unintended consequences (Giddens 1984, pp. 10-11).
Therefore, the production and reproduction of structure by human agents might result in unacknowledged conditions that feed back into individuals' actions, leading to a different, maybe undesirable, behavior (Giddens 1984, p. 5).

These unintended consequences of actions might give rise to emergent properties of social structure (Archer 2010). In the social sciences, the core theoretical property of emergence itself is non-intentionality (Mayntz 2011). This view opposes the morphogenetic approach (Archer 2010) as advocated in general systems theory, which is often applied in the natural sciences. The latter view posits that phenomena are irreducibly layered (Hodgson 2007), such that a whole has "properties which make the whole entity more than the sum of its parts" (Checkland 1998, p. 50, emphases removed).

It follows from these observations that the way in which social structure is created and re-created cannot be determined fully by any single actor, but unfolds dynamically and on a collective level, based on the intended and unintended consequences of the actions performed by individuals.

\subsubsection{Routinization and Social Structure}

Giddens (1984) (p. 60) points out that the concept of routinization is vital to the theory of structuration since it links the continuity of the agent's personality in his or her performance of day-today activities to the institution of society. In effect, social structure is sustained only if it is regularly reproduced. Giddens (1984) posits that a routine in day-today business "is psychologically linked to the minimizing of unconscious sources of anxiety," while "in the enactment of routines individuals sustain a sense of ontological security" (p. 282). Moreover, only routinization enables human actors to reflexively analyze actions that are "distinctively 'the same' across space and time" (Giddens 1984, p. 3). On a collective level, social systems are conceived as "reproduced relations between actors and collectivities, organized as regular social practices" (Giddens 1984, p. 25) without which an institution would cease to exist.

\subsubsection{Adaptations of Structuration Theory in the IS Discipline}

Whereas structuration theory is focused on social structures and makes little refer- 
ence to technology, adaptations to structuration theory, such as adaptive structuration theory (AST) (DeSanctis and Poole 1994) and the practice lens account (Orlikowski 2000) add an IS perspective to the debate (Jones and Karsten 2008). AST argues that IT, work tasks, and the environment can be sources of structure and that the structures IT provides can be described in terms of their structural features (i.e., the properties of the IT artifact) and in terms of the spirit of the feature set (i.e., the use of an artifact in a way that its designers either intended or did not intend). In their actions, users are free to appropriate (or not appropriate) an IT artifact and might do so faithfully or unfaithfully (i.e., consistent or inconsistent, respectively, with the spirit of the feature set). Interactions between users and the technology are assumed to be subject to the dialectic of control, in which either one is shaped by the other. The practice lens account is built on the premise that technology structures are emergent and cannot be embodied into the design, correcting Orlikowski's (1992) view of a duality of technology as stated some years before (Jones and Karsten 2008). Jones and Karsten (2008) show that Giddens neglects how IT artifacts and human actions are interrelated and identify affordances (Gibson 1979) as one potential element of such an account. Affordances refer to the actionable properties between the world and an actor (Norman 2004; Jones and Karsten 2008). Thus, in line with Jones and Karsten (2008), technology is "not seen as determining action, but rather as defining a space for potential action" (p. 150).

\subsection{Organizational Routines' Ostensive and Performative Properties}

Based on structuration theory, which highlights the importance of routines for the individual and for the constitution of society and institutions, the theoretical concept of organizational routines that is discussed in organization science provides a lens through which to identify the forces that operate in the construction and reconstruction of structure in day-to-day business. In a seminal review, Becker (2004) traces the theoretical concept of organizational routines back to Nelson and Winters' (1982) work on economic change as evolution that builds on organizational routines as the central unit of analysis and identifies a set of core properties of organizational routines (see Table 1 and Beverungen (2013) for details).

A crucial question is whether organizational routines are viewed as mindless actions or as effortful accomplishments. In the former understanding, routines are carried out subconsciously without requiring attention. In the latter understanding, routines require cognitive effort, which means that they are open to variation. In this regard, Feldman and Pentland (2003) contend that organizational routines have both ostensive and performative aspects. Whereas the ostensive aspects are an ideal or schematic form of the routine, the performative aspects denote concrete actions carried out by individuals in specific places at specific times, so individuals choose how they carry out the routine. On a collective level the performance of the routine produces and reproduces its ostensive aspects. This view reflects the duality of structure and agency, in line with structuration theory (Giddens 1984).

\section{Related Work in BPM Research}

In order to elicit the consideration of the presented theories in BPM research, a review of the literature in the top basket of IS journals was performed, in addition including BISE/WIRTSCHAFTSINFORMATIK to account for the long research tradition of BPM research in the German-speaking community. A first screening for the term business process produced many papers that had only marginal connections to the topic, so a second search was performed for papers that contained the term business process either in their abstract or as a keyword (in German papers, the search term Geschäftsprozess* was utilized). Only research articles were included, while excluding other article types such as stateof-the-art articles, discussion articles, and editorials. This selection was made, since it was assumed that only completed research articles would be sufficiently long to introduce the theories in depth. This search produced 155 papers, most of which were published in BISE/WIRTSCHAFTSINFORMATIK (37 papers), followed by JSIS (30), JMIS (29), ISR (14), JIT (12), EJIS (11), ISJ (9), MISQ (8), and JAIS (5). In order to further extend this selection, the book chapters published in the Handbook on Business Process Management (vom Brocke and Rosemann 2010a, 2010b), which is a comprehensive and timely overview on BPM, were included as well, so the sample of papers analyzed contained 208 articles in total. All papers supporting an electronic search ${ }^{1}$ were screened for the major theoretical concepts identified in Sect. 2, to identify the papers best related to this study.

The review identified few papers that considered the presented theories. For example, Giddens' work is referred to only in Willcocks and Smith (1995), Nandhakumar et al. (2005), and Saravanamuthu (2002), whereas adaptive structuration is referred to only in Nagasundaram and Bostrom (1994) and Srivardhana and Pawlowski (2007). Neither of the latter papers cites Giddens or refers explicitly to the two main concepts of AST, that is, structural features and the spirit of the feature set. Emergence is referenced as a theoretical concept only in Nandhakumar et al. (2005) and in Shaw and Holland (2010), although the term is frequently used in its everyday meaning, to denote something that is proliferating. Drift is mentioned in six papers but is explored further only in Nandhakumar et al. (2005), which is also the only paper to discuss the duality of technology. Organizational routines were discussed explicitly in five papers, albeit the performative and ostensive properties of routines were not identified as interplaying to develop structure. Newell et al. (2000) and Boersma and Kingma (2005) were the only papers in the sample to explicitly refer to the three steps of design, sense-making, and negotiation as important for the design and appropriation of technology.

In the following, the papers best related to this study are presented.

In their in-depth case study on implementing ERP systems, Nandhakumar et al. (2005, p. 221) theoretically conceptualize "triggers and consequences of the cycles of control and drift." The study offers rich insights based on a strong theoretical foundation that includes drift, structuration theory, adaptive structuration theory, technological

\footnotetext{
${ }^{1} \mathrm{~A}$ minority of the older papers were available as scanned documents only, restricting an electronic search of the keywords. In these papers, a manual inspection was conducted to assess their relevance for this study.
} 
Fig. 1 Conceptualizing the interplay of the design of IT artifacts for business

processes and the emergence of business processes as organizational routines, extension of the framework proposed by Pentland and Feldman (2008)

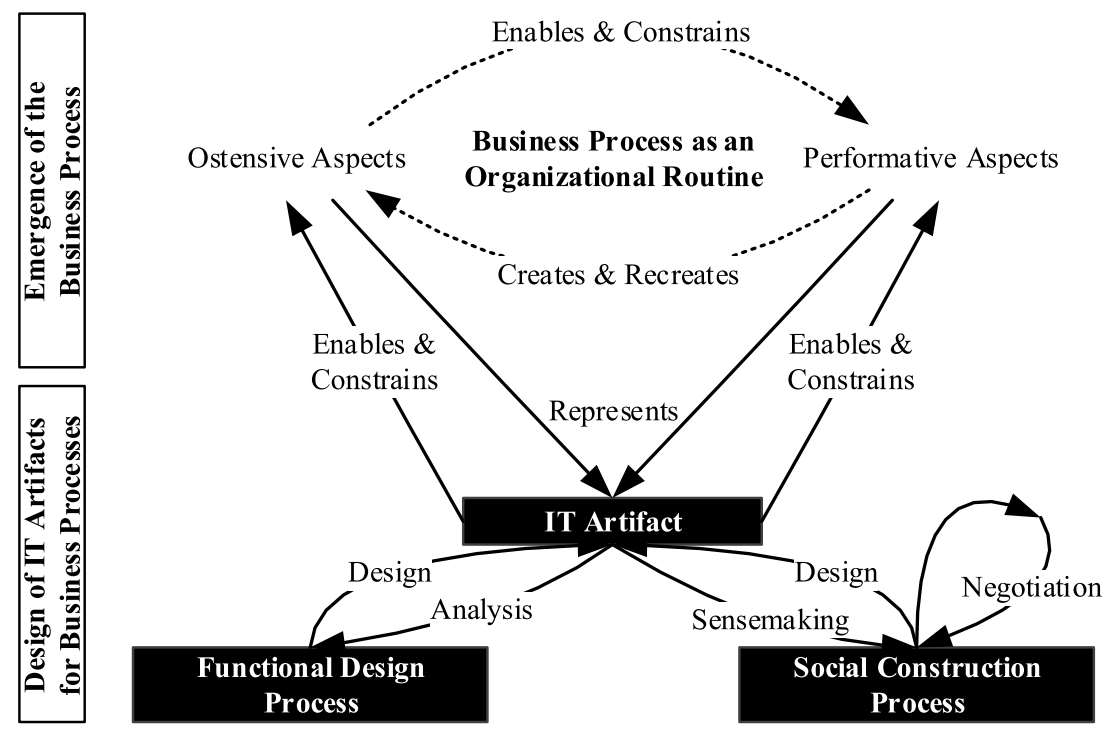

affordances, social structures, and Actor Network Theory (ANT). Based on their observations derived in the case study, they identify cycles of control and drift in an ERP implementation process that result from cycles of designers' and users' intentional interactions, the affordances of the technical system, and the prevailing social structures in the company. However, the paper is focused on the ERP implementation process without considering business processes explicitly or identifying connections to the literature on organizational routines and their ostensive and performative aspects.

Some studies discuss the identified concepts somewhat remotely. Schäfermeyer et al. (2012) argue that business process complexity, conceptualized amongst others as non-routineness, inhibits business process standardization. Therefore, they propose routines to be a property of a business process, but do not explicitly relate both concepts to each other. Newell et al. (2000) develop a diffusion model for the spread of ideas and knowledge that underpin complex technologies, exemplified with business process re-engineering and packaged software. In line with the literature on the Social Construction of Technology (Weick 1976), they emphasize that knowledge conveyed by and appropriated from technology must be incorporated into the user firm through a process of negotiation and sense-making (Newell et al. 2000, p. 254) by embedding it into the organization's existing routines and practices. Boersma and Kingma's (2005) case study shows that ERP implementation necessitates processes of design, sense-making, and negotiation and that
ERP implementation is closely related to altering working routines in the company. Sarker et al. (2006) use concepts from ANT to interpret the chain of events that led to business process change failure in an interpretive case study. Bala and Venkatesh (2007) and Wang et al. (2013) refer to organizational routines in their studies but refrain from investigating the interplay between these routines' ostensive and performative aspects in the process of structuration. Srivardhana and Pawlowski (2007) mention routines in their study on the relationships of ERP-related knowledge impacts and the absorptive capacity for business process innovation but do not apply (adaptive) structuration theory. Nagasundaram and Bostrom (1994) develop a framework for creative processes that is based on adaptive structuration theory and view creativity techniques as "providing a set of structures that enable, promote, or constrain certain kinds of group interaction and communication" (p. 100) that are appropriated by users or not, leading to emergent structuring mechanisms. While the understanding of structure as embodied in mechanisms is inconsistent with structuration theory, the article makes a rich account of the interplay between structures and their appropriations by human actors. However, no reference to organizational routines and their ostensive and performative aspects is drawn, and the paper does not focus on business processes. Saravanamuthu (2002) identifies IS approaches, such as BPM, as "social constructions that shape and are shaped by the tensions between the prevailing ideology of economic rationalism and alternative means of achieving sustainable goals for the wider society" (p. 85), recognizing structurational analysis as a device to identify contradictions in work relations that may influence the social construction of IS approaches. Kawalek (1994) highlights the value of interpretivist approaches, such as structuration theory, for better understanding methods in BPR which "can be largely described as positivistic in nature" (p. 278).

\section{A Meta-Framework on the Interplay of the Design and Emergence of Business Processes as Organizational Routines}

The observations that IT artifacts are designed in a top-down fashion, whereas business processes as organizational routines emerge as social structures based on the intended and unintended consequences of human action, motivates the design of a meta-framework (Fig. 1) that describes the interplay of both viewpoints.

As regards design, two perspectives are taken that influence the design of IT artifacts, inspired by Becker et al. (2013). On the one hand, design is a rational engineering effort, based on identifying requirements of the environment in which an IT artifact is intended to function (Alexander 1970), designing the IT artifact, and evaluating the artifact's utility (March and Smith 1995). On the other hand, design is a social process (Avison et al. 1998; Bijker 1987; Rosenkranz 2011) that is shaped by the intentions of the 
Table 1 Identifying business processes as organizational routines, based on the properties of routines (Becker 2004)

\section{Properties of organizational routines}

Routines are patterns of actions, activities, behavior, or interactions that are carried out in organizations.

Routines are recurrently performed in an organization.

Routines have a collective nature. They involve multiple actors that are distributed across space or across the organization and might have dispersed knowledge.

Routines are effortful accomplishments of individuals. They have performative and ostensive aspects, interacting with each other as a mutually constitutive duality.

Routines have a processual character in the sense that they are subject to organizational change.

Routines are context-dependent, embedded into organizations, and specific to this context.

Routines are path dependent.

Routines are triggered by actors or by other routines.

\section{Properties of business processes}

Business processes are patterns of actions that can be identified and documented in business process models.

Business processes are designed and implemented (or discovered and analyzed) only if they are performed frequently enough.

Business processes often involve diverse organizational units (e.g., departments or companies) that have been formed due to the division of labor.

Business processes can be carried out differently by people in an organization. Based on analyzing the enactments in interviews or with process mining techniques, patterns of action can be discovered.

Business processes can change evolutionary, or revolutionary as a result of disruptive business process re-engineering initiatives.

Business processes can be a source of competitive advantage. Reference processes need to be adapted to fit the idiosyncratic properties of organizations.

Business process changes must at least comply with the organizational and IT infrastructures onto which the processes are built. In this sense, processes are path dependent.

Business processes are started by human actors or by business processes which trigger events that are preconditions for other business processes.

\section{Effects of business processes}

Effects of organizational routines

Business processes coordinate the actions of multiple people from multiple departments or organizations in an end-to-end fashion.

systematicity, re-integrating knowledge dispersed by a "segmentation of the institutional order" (Berger and Luckmann 1966, p. 82).

Routines represent a 'truce' between the actors that legitimates actions.

Routines provide stability that allows people to economize on their cognitive resources for information-processing and decision-making by focusing their attention on non-routine events.

Routines are part of the organizational memory and can store tacit operational knowledge, including knowledge on the activities and their coordination.
Business processes are designed as standard operating procedures, such as in mass transaction processing carried out in ERP systems. The legitimation of the processes is not constantly questioned by the actors.

Business processes represent standard operating procedures required for running the business. Operational excellence of these procedures frees up resources for building dynamic capabilities.

Business process models codify knowledge about business processes, so it can be stored in the organizational memory and triangulated with other knowledge. involved actors and their social relationships. Since these intentions can contradict each other, the designers might have to remedy their conflicts in processes of design, sense-making, and negotiation (Lyytinen et al. 2008).

As regards the emergence of business processes as organizational routines, the meta-framework builds on the seminal work of Pentland and Feldman (2008) who outline that organizational routines rely on an interplay of their ostensive and performative aspects that can be influenced (but not determined) by technology, i.e., by IT artifacts. The IT artifact, therefore, assumes the crucial nexus between the design of IT artifacts and the emergence of business processes. Whereas performances are particular enactments of an organizational routine by human actors that are en- abled and constrained by their ostensive aspects, the ostensive aspects of the routine themselves are continuously produced and reproduced by performative aspects.

The components of the meta-framework are described in the following sections.

\subsection{Business Processes Viewed as Particular Organizational Routines}

Becker (2004) identifies eight characteristics of organizational routines against which business processes can be viewed as organizational routines (Table 1). Consistent with BPM literature, the position taken in this paper is that business processes are the subset of organizational routines that represent "endto-end work across an enterprise that creates customer value" (Hammer 2010, p. 4). On the other hand, this viewpoint implies that organizational routines that do not represent end-to-end work and do not cross organizational boundaries should not be viewed as business processes. Consider rather informal organizational routines that support the recognition and assimilation of new knowledge (Jones and Macpherson 2006). For instance, a "New Product Development Committee" can be an institutionalized routine for conducting meetings to evaluate new product ideas and reporting on the progress of ideas that have been implemented into the organization (Jones and Macpherson 2006, p. 163). Albeit theoretically it is possible to view these meetings as a sequence of work activities, they do not out of themselves provide value to customers in an end-to-end 
fashion. Therefore, these routines do not fall under the abovementioned definition of a business process. Apart from this theoretical argument, it seems quite unlikely that a company would manage meetings for knowledge exchange and new product development as business processes, nor would they likely use the common suite of BPM tools for modeling, discovering, analyzing, and improving the sequence of activities in these meetings.

\subsection{Business Processes as Subject to a Duality of Structure}

It follows from the observation that business processes are a subset of organizational routines that business processes can be researched based on the theoretical foundations of organizational routines. For instance, business processes feature both ostensive and performative aspects, just as organizational routines do (Feldman and Pentland 2003; Pentland and Feldman 2008). Consistent with Giddens' (1984) structuration theory, these two aspects are related in a mutually constitutive duality. Common manifestations of the performative aspects of a business process are instantiations of workflows, such as the purchaseto-pay or order-to-cash processes administrated in ERP systems, and are reflected in the memory traces of the human actors who perform these processes. The ostensive aspects of a business process denote the ideal or schematic forms of the routine (Pentland and Feldman 2008) that enable and also constrain the enactments of the routine in the performance of knowledgeable human actors.

The interplay of the ostensive and performative aspects of a business process is subject to a duality of structure (Giddens 1984). On the one hand, the enactments of the ostensive aspects of a business process guide the performative aspects as templates, legitimate desired or de-legitimate undesired types of performances of business processes, and refer to sets of actions that could otherwise remain incomprehensible (Becker et al. 2013; Feldman and Pentland 2003). On the other hand, the performative aspects of a business process create and re-create the ostensive aspects as abstract patterns. Since the ostensive aspects of a routine are "the understandings (embodied as well as cognitive) of the participants" (Pentland and Feldman 2008, p. 241), there might be more than one ostensive aspect of a business process.

\subsection{IT Artifacts as Representing, Enabling and Constraining Business Processes}

In their article on the folly of designing artifacts while hoping for patterns of action (that is the title of the cited article) Pentland and Feldman (2008) propose that the ostensive and performative aspects of organizational routines and, therefore, business processes - are closely related to (IT) artifacts. However, the authors emphasize that it is impossible to design the routines themselves, as designers can only design IT artifacts that represent (e.g., model) ostensive or performative aspects of a routine, whereas IT artifacts influence both aspects of the routines. IT artifacts do not determine how organizational routines will be performed or created. In this way, misunderstanding routines as 'things' represents a strong form of technological determinism of the artifact on the routine and should be avoided (Pentland and Feldman 2008).

Pentland and Feldman's (2008) view is consistent with structuration theory in that it emphasizes that structure "cannot be inscribed or embedded in technology, since to do so would give it an existence separate from the practices of social actors," contradicting the duality of structure (Jones and Karsten 2008, p. 132). In addition, structure that resides in a material artifact is ontologically different from social structure that is created only by the practices of social actors (Jones and Karsten 2008). However, Giddens (1984, p. 177) recognizes that individuals' actions take place in the context of constraints imposed by the human body and the material world, social sanctions by other agents, and structural constraints given by society vis-à-vis situated actors. These constraints limit the range of options available for an actor.

Arguably, the constraints of the human body and the material world are closely related to IT artifacts since the affordances of artifacts are designed to augment but might also constrain the range of opportunities for humans to act. Therefore, enacting the affordances might provide human actors with a "power" over objects and other actors (Giddens 1984, pp. 174-179) that they would not have had without using the artifacts, but enacting these affordances might also deny them power. Constructs, models, methods, and instantiations (March and Smith 1995) clearly own these properties since they might, e.g., enable users to communicate with people outside the organization (e.g., by sending them invoices), but they also constrain these actions (e.g., by having to comply with the data structure of an invoice and with the business process that includes sending the invoice). Thus, IT artifacts might exert material agency (Jones 1998) by presenting affordances that human actors can decide to appropriate faithfully or unfaithfully. These affordances enable and also constrain the different ways of performing of an organizational routine, just as the ostensive aspects of the routine do.

As Pentland and Feldman (2008) note, IT artifacts can represent organizational routines even if this representation is necessarily incomplete, since organizational routines can convey tacit knowledge (Becker 2004) that cannot be codified. If organizational routines are performed in workflow management systems and leave data traces such as an event log, process mining (van der Aalst and Weijters 2004; van der Aalst et al. 2003) and organizational mining (Song and van der Aalst 2008) can be valuable tools for mapping the performances of business processes with workflow nets, discovering and enhancing the abstract patterns of the routines, and for conformance checking between the ostensive and performative aspects of a routine (van der Aalst 2011). First moves to make process mining usable as a toolbox for discovering and analyzing organizational routines have been performed by Pentland et al. (2009) and Breuker and Matzner (2013). With respect to identifying the ostensive aspects of a routine, IT artifacts can represent the abstract patterns of a routine even without the presence of an event log. A case in point are business process re-engineering projects in which the 'typical' control flow of a routine is identified in interviews and then modeled, analyzed, improved, and implemented into application systems. These models can be designed in a centralized manner as well as in a decentralized fashion by the users themselves, such as with a subject-oriented BPM approach (Fleischmann et al. 2012).

Designers develop IT artifacts in order to foster the efficiency of business processes that are carried out by users based on appropriating their affordances. 
As noted in AST, the intentions of the designers and users are not necessarily compatible and may even contradict each other such that the business processes performed deviate from those envisioned by the designers of the IT artifacts. In addition, the performances of a business process necessarily result in both intended and unintended consequences so that the social structures produced and reproduced by these performances are not fully foreseeable, let alone designable.

\subsection{IT Artifacts as Subject to Functional-Hierarchical Design and Social Construction of Technology}

IT artifacts that enable business processes cannot be designed with respect only to their functional properties but must also reflect the properties of the social system in which the design takes place (Becker et al. 2013; Sein et al. 2011).

The design of IT artifacts is often conceptualized as a functional-hierarchical engineering process that is based on the principles of decomposition and modularity (Becker et al. 2013). A modular system compromises of a set of modules that communicate with each other based on standardized interfaces (Langlois 2002). Such systems tend to be highly adaptable and require little coordination (Sanchez and Mahoney 1996; Weick 1976). In the context of IT artifacts for organizational routines, these engineering processes might be carried out by analyzing the organizational routine to be supported and designing an IT artifact to enable this or an adapted organizational routine.

Since organizational routines are collective patterns of actions, the design of IT artifacts for enabling and constraining organizational routines might also be understood as a process of social construction that is beyond the influence of individual designers (Becker et al. 2013). For information systems design in general, similar approaches have been suggested (Avison et al. 1998; Rosenkranz 2011). This view refers back to the concept of drift, including multiple actors with potentially conflicting interests that need to work together to design IT artifacts that support an organizational routine. Social construction of technology (Bijker 1987; Howcroft et al. 2004) has been argued to include the key phases of design, sensemaking, and negotiation (Lyytinen et al. 2008). Design refers to the development of IT artifacts such as conducted in engineering processes based on functional design. Subsequently, other actors work out a fit between the design and their own objectives. Since the views of different actors might be conflicting, negotiations could be necessary to resolve the conflicts, leading to a design that is acceptable for all actors involved in the design process.

\section{Contributions}

This paper offers a managerial contribution, and four contributions to the theory on the design of IT artifacts and the emergence of business processes as organizational routines.

First, the paper suggests a departure from the assumption that business processes can be designed solely in processes of functional design based on decomposing process design into hierarchical levels that are aligned with corporate strategy. Although many BPM papers seem to make this assumption implicitly, it contradicts the observation that information infrastructures are at drift (Ciborra and Hanseth 1995), identifying the impossibility of complete control that is proliferating in the context of modernity (Giddens 1991). Since infrastructures are at drift, so are business process infrastructures.

Second, to remedy this conflict, this paper offers a conceptual meta-framework with which to conceptualize the interplay between the design of IT artifacts and the emergence of business processes as organizational routines. The meta-framework is based on two propositions: First, the design of IT artifacts for business processes cannot be performed solely in processes of functional decomposition (Becker et al. 2013; Sein et al. 2011), but IT artifacts are shaped by 'messy' processes that are influenced by the social system into which the design is embedded. This claim is in line with literature that views the development of IT artifacts as cycles of design, sense-making, and negotiation (Lyytinen et al. 2008). The second proposition on which the metaframework is based is that providing IT artifacts which can be used to perform business processes cannot guarantee that users will appropriate these artifacts' affordances as intended; instead, users are free to decide how to perform business processes in their day-to-day work. This claim is in line with the literature on the interplay between organizational routines and artifacts (Pentland and Feldman 2008) and adaptive structuration theory (DeSanctis and Poole 1994). It follows that the (perceived) affordances of IT artifacts enable and constrain but do not determine the performances of business processes with their material agency. At the same time, the ostensive aspects of the business process also enable and constrain the performances of a business process. In turn, the performances of business processes create and recreate the ostensive aspects of the business process. This mutually constitutive relationship can be thought of in terms of a duality of structure as it was first proposed in the structuration theory contributed by Giddens (1984). The meta-framework can, therefore, be a step towards framing BPM "as a contextual, organizational and managerial concept [...] [that needs] to be exposed to phenomenological and interpretivist approaches to research" (Kawalek 1994, p. 278).

Third, the paper provides an in-depth overview of the coverage of the theoretical concepts in the BPM body of knowledge that has been published in the IS top-tier journals since 1988 and in BISE/ WIRTSCHAFTSINFORMATIK since 1999. 155 papers that include the search term business process in their abstracts or keywords were identified. Among the journals, BISE/WIRTSCHAFTSINFORMATIK offers the broadest forum for publishing BPM papers, but an in-depth review of papers from this sample and from the prospective book on BPM research (vom Brocke and Rosemann 2010a, 2010b) revealed that few BPM papers cover the theories discussed. The most comprehensive accounts are from Nandhakumar et al. (2005) and Newell et al. (2000), but while the former paper does not discuss how organizational routines elicit the inner workings of structuration in a business process context, the latter paper does not explicitly refer to structuration theory or its IS successor theories. The papers published on BPM in BISE/WIRTSCHAFTSINFORMATIK almost completely neglect the discussion of any of the theoretical foundations presented in this paper. As illustrative examples, only a handful of papers refer to emergence (Coldewey 2002; Wittmann and Bruckner 2007), to Giddens and his structuration theory (Riemer and Filius 2008), to adaptive structuration theory (Klein and Krcmar 2003; 
Riemer and Filius 2008), to drift or Ciborra (Teubner 2013), or to (organizational) routines (Brüggemeier et al. 2005; Lammers 2004; Schäfermeyer et al. 2012; $\mathrm{Yu}$ 2001) at all. Since none of these papers, apart from the above-mentioned article by Schäfermeyer et al. (2012), has a clear focus on business processes, the proposed meta-framework strives to develop an alternative theoretical view on BPM to bridge this gap.

Fourth, the meta-framework points at two inherent theoretical constraints for design science and design research (Winter 2008) on IT artifacts for business processes. In its most basic form, the design of IT artifacts comprises two activities: to design and to evaluate (March and Smith 1995). Although different views on the theory infusion of design processes exist (Fischer et al. 2010), seminal papers state that design research is on a dual mission to contribute to management and theory: On the one hand, the designed IT artifact should provide utility to solve a particular problem in an organization. On the other hand, the properties of the IT artifact are supposed to be generalizable to a design theory (Gregor and Jones 2007) that solves a class of problems. However, anecdotal evidence suggests that not many authors have managed to satisfy both requirements equally well. In this regard, the developed metaframework points at two inherent theoretical difficulties that might provide an at least partial explanation. First, the design of IT artifacts for business processes is often subject to processes of social construction that are more difficult to manage than processes of functional design, since they are influenced by activities of sense-making and negotiation. These negotiations might not always reflect sensible design decisions, but reflect the 'messy' everyday world of business, influenced by power asymmetries and deals. It seems reasonable to assume that processes of social design will, therefore, lead to idiosyncratic changes to be made to the IT artifact, inhibiting its close reliance on theory and its generalizability to fit other instances of the same problem. Second, the meta-framework suggests that the evaluation of an IT artifact in its natural environment is inherently difficult. On the one hand, the IT artifact might be appropriated unfaithfully by the people in the organization (Poole and DeSanctis 2004) or might be subject to different phenomena of resistance (Bagayogo et al. 2013), leading to undesired performances of the organizational routine. On the other hand, even if the users strive to appropriate the IT artifact faithfully, the unintended consequences of their actions might lead to the additional performance of different variants. Structuration theory suggests that in the case that these performances of the routine were repeated frequently enough, new (and possible undesired) ostensive aspects of the routines would emerge. Both effects suggest that the routines performed in an organization will to some extent differ from the original plan engineered by the designers. For design scientists, this observation has the troubling consequence that observing effective and efficient performance of a business process in an organization can hardly be traced back to the properties of the IT artifacts that enable these routines. Thus, a straightforward 'proof' of the utility of an IT artifact, as often demanded from design researchers to justify their design decisions in research papers, remains a necessarily incomplete, if not an impossible, endeavor.

The managerial contribution this paper offers is to remind business process managers that the installation of welldesigned IT artifacts, such as workflow management systems, ERP systems, and business process models, is no guarantee that business process performance will be high. IT artifacts can be used to perform business processes in the day-today work in companies, but they might not be used at all or be used in a way that is inconsistent with their designers' intentions. Performances of the routine shape the general ideas concerning 'how we perform a business process in this organization' (the ostensive aspects). The bad news is that managers should not necessarily treat apparently low business process performance as deficiencies of IT artifacts that can be identified in root cause analyses, nor should they assume that business process reengineering initiatives (leading to new IT artifacts) can resolve the problem. The good news is that human actors can adapt business processes and IT artifacts to perform business processes that differ from those the designers had in mind when developing the IT artifacts. After all, positive deviances of a business process can tailor the process to fit idiosyncratic situations of customers and thus, for instance, deal with different forms of variability (Frei et al. 1999). Repetitively conducting business processes in different ways will result in the emergence of new organizational routines and lead to an evolution of the organizations that might extend top-down reorganization endeavors with a bottom-up process.

\section{Research Outlook}

While the developed meta-framework is envisioned to be applicable to the design and emergence of business processes in general, it particularly enables research in scenarios that are beyond the control of any individual organization. Some examples might illustrate this claim.

First, we have argued that service is subject to a co-creation of value of service providers and service customers (Vargo and Lusch 2004), such that service business processes need to be carried out in cooperation of both actors. It follows that the design of IT artifacts for organizational routines carried out to deliver service, also termed interaction routines, is outside the control of any of the actors and needs to be performed cooperatively (Becker et al. 2013). Since both parties enact the interaction routines as effortful accomplishments, new variants of the interaction routines are being performed. The variants performed frequently enough will then be retained as ostensive interaction routines, representing a 'truce' between the actors as well as coordinate their actions based on an implicit exchange of knowledge. The interplay of the design of IT artifacts that enable these interaction routines (Becker et al. 2013) and the emergence of the resulting interaction routines can be studied by means of the theoretical concepts supplied by the proposed meta-framework.

Second, Ciborra and Hanseth suggest that modernity (Giddens 1991) and the rise of globally distributed business process infrastructures further lead to a "loosening-up of time-space constraints[,] the diffusion of systems that process information and knowledge [, and] the increasing pace of learning by economic and social institutions" (Ciborra and Hanseth 1995, p. 7). In these settings, unintended side effects can travel faster and more forcefully, increasing unpredictability. An illustrative example are instantiating business processes on open application systems 


\section{Abstract}

Daniel Beverungen

\section{Exploring the Interplay of the Design and Emergence of Business Processes as Organizational Routines}

Much of the BPM literature views business process design and implementation as a top-down process that is built on strategic alignment and managerial control. While this view has enabled the design of many IT artifacts for business processes, it is inconsistent with the observation that information infrastructures, including a company's business process infrastructure, are at drift, a term that refers to the lack of topdown management control. The paper contributes to resolving this inconsistency by developing a meta-framework that conceptualizes business processes as emergent organizational routines that are represented, enabled, and constrained by IT artifacts. IT artifacts are developed in processes of functionalhierarchical decomposition and social design processes. Organizational routines have ostensive and performative aspects, forming a mutually constitutive duality. A literature review demonstrates that the propositions offered by the meta-framework have been insufficiently considered in the BPM field. The paper concludes with an outlook to applying the meta-framework to theorize about the interplay of design projects with the subsequent emergence of business processes in organizations.

Keywords: Business process management, Organizational routine, Structuration theory, Emergence, Design, Social construction of technology
(Richter and Riemer 2013), such as online social network sites (SNS). Rosemann et al. (2011) propose that IT artifacts such as SNS are digital complementary assets that benefit from interactions with many users who participate on the platforms free of charge. Companies have begun to exploit the business potential offered by SNS by tapping into these digital complementary assets. For instance, airline companies such as KLM offer business processes for booking flights and seats in airplanes on Facebook or LinkedIn (KLM 2014). Since airline companies do not own Facebook and their interactions with customers may be visible to other people the customer is networked with, this business process might emerge particularly quickly, denying airline companies control over how the process might be altered. Another even more uncontrollable scenario are business processes that are conducted or influenced by intelligent objects in Cyber-Physical Systems (CPS), in which "embedded computers and networks monitor and control the physical processes, usually with feedback loops where physical processes affect computations and vice versa" (Lee 2008). While each of the devices operates on local information, networking the physical objects with each other and with distributed information systems can enable self-organizing scenarios like the 'smart factory' or 'smart mobility'. Since the behavior of all the involved objects cannot be fully predicted and since additional objects might enter the CPS at any time, the resulting business processes are not deterministic and cannot be controlled fully on the level of the CPS. Likewise, CPS-based scenarios might be assumed to lead to a particularly high degree of drift in a business process infrastructure. Studying the emergence of business processes in these scenarios, therefore, represents a prime area of applying the theoretical constructs proposed in this paper in empirical research.

\section{References}

Alexander C (1970) Notes on the synthesis of form. Harvard University Press, Cambridge Archer MS (2010) Morphogenesis versus structuration: on combining structure and action. The British Journal of Sociology 61(1):225-252

Avison D, Wood-Harper A, Vidgen R, Wood $J$ (1998) A further exploration into information systems development: the evolution of multiview. Information Technology \& People 11(2):124-139
Bagayogo F, Beaudry A, Lapointe L (2013) Impacts of IT acceptance and resistance behaviors: a novel framework. In: 34th International conference on information systems, Milan, Italy

Bala $H$, Venkatesh V (2007) Assimilation of interorganizational business process standards. Information Systems Research 18(3):340-362

Becker J, Beverungen D, Knackstedt R, Matzner M, Müller O, Pöppelbuß J (2013) Designing interaction routines in service networks: a modularity and social construction-based approach. Scandinavian Journal of Information Systems 25(1):17-48

Becker MC (2004) Organizational routines: a review of the literature. Industrial and Corporate Change 13(4):643-677

Berger PL, Luckmann T (1966) The social construction of reality: a treatise in the sociology of knowledge. Doubleday, Garden City

Beverungen D (2013) On the design of IT artifacts and the emergence of business processes as organizational routines. In: 34th International conference on information systems, Milan, Italy

Bijker W (1987) The social construction of bakelite: toward a theory of invention. In: Bijker W, Hughes TP, Pinch T (eds) The social construction of technological systems. MIT Press, Cambridge, pp 159-187

Boersma K, Kingma S (2005) From means to ends: the transformation of ERP in a manufacturing company. The Journal of Strategic Information Systems 14(2):197-219

Breuker D, Matzner M (2013) Statistical sequence analysis for business process mining and organizational routines. In: $21 \mathrm{st}$ European conference on information systems, Utrecht, Netherlands

Brüggemeier M, Dovifat A, Kubisch D (2005) Analyse von Innovationsprozessen im Kontext von E-Government. WIRTSCHAFTSINFORMATIK 47(5):347-355

Checkland P (1998) Systems thinking. In: Currie WL, Galliers RD (eds) Rethinking management information systems. Oxford University Press, Oxford, pp 45-56

Ciborra CU (1997) De profundis? Deconstructing the concept of strategic alignment. Scandinavian Journal of Information Systems 9(1):67-82

Ciborra C, Hanseth O (1995) Introduction. In: Ciborra C, Braa K, Cordella A, Dahlbom B, Failla A, Hanseth O, Hepso V, Ljungberg J, Monteiro E, Simon K (eds) From control to drift: the dynamics of corporate information infrastructure. Oxford University Press, Oxford, pp 1-11

Coldewey J (2002) Agile Entwicklung Webbasierter Systeme. WIRTSCHAFTSINFORMATIK 44(3):237-248

DeSanctis G, Poole MS (1994) Capturing the complexity in advanced technology use: adaptive structuration theory. Organization Science 5(2):121-147

Feldman MS, Pentland BT (2003) Reconceptualizing organizational routines as a source of flexibility and change. Administrative Science Quarterly 48(1):94-118

Ferneley EH, Sobreperez P (2006) Resist, comply or workaround? An examination of different facets of user engagement with information systems. European Journal of Information Systems 15(4):345-356

Fischer C, Winter R, Wortmann F (2010) Gestaltungstheorie. WIRTSCHAFTSINFORMATIK 52(6):383-386

Fleischmann A, Schmidt W, Stary C, Obermeier S, Börger E (2012) Subject-oriented 
business process management. Springer, Heidelberg

Frei FX, Kalakota R, Leone AJ, Marx LM (1999) Process variation as a determinant of bank performance: evidence from the retail banking study. Management Science 45(9):1210-1220

Gibson J (1979) The ecological approach to perception. Houghton Mifflin, London

Giddens A (1984) The constitution of society, vol 20(3). Polity Press, Cambridge

Giddens A (1991) The consequences of modernity. Stanford University Press, Palo Alto

Gregor S, Jones D (2007) The anatomy of a design theory. Journal of the Association for Information Systems 8(5):312-335

Hammer M (2010) What is business process management? In: Vom Brocke J, Rosemann $M$ (eds) Handbook on business process management, vol. 1. Introduction, methods, and information systems. Springer, Heidelberg, pp 3-16

Harmon P (2010) The scope and evolution of business process management. In: Handbook on business process management, vol. 1. Introduction, methods, and information systems. Springer, Heidelberg, pp $37-$ 82

Hodgson GM (2007) Institutions and individuals: interaction and evolution. Organization Studies 28(1):95-116

Howcroft D, Mitev N, Wilson M (2004) What we may learn from the social shaping of technology approach. In: Mingers J, Willcocks L (eds) Social theory and philosophy for information systems. Wiley, Chichester, pp 329-371

Ignatiadis I, Nandhakumar J (2009) The effect of ERP system workarounds on organizational control: an interpretivist case study. Scandinavian Journal of Information Systems 21(2):59-90

Jones MR (1998) Information systems and the double mangle: steering a course between the scylla of embedded structure and the charybdis of strong symmetry. In: Larsen TJ, Levione L, DeGross JI (eds) Information systems: current issues and future changes. Springer, Heidelberg, pp 287-302

Jones MR, Karsten H (2008) Giddens's structuration theory and information systems research. Management Information Systems Quarterly 32(1):127-157

Jones O, Macpherson A (2006) Interorganizational learning and strategic renewal in SMES. Long Range Planning 39(2):155-175

Kane GC, Labianca G (2011) IS avoidance in health-care groups: a multilevel investigation. Information Systems Research 22(3):504-522

Kawalek JP (1994) Interpreting business process re-engineering on organization work flow. Journal of Information Technology 9(4):276-287

Kim HW, Kankanhalli A (2009) Investigating user resistance to information systems implementation: a status quo bias perspective. Management Information Systems Quarterly 33(3):567-582

Klein A, Krcmar H (2003) Electronic meeting systems paradox. WIRTSCHAFTSINFORMATIK 45(4):421-433

KLM (2014) KLM meet and seat. http://www. $\mathrm{klm} . c o m /$ travel/gb en/prepare for travel/ on_board/your_seat_on_board/. Accessed 2014-01-13

Lammers M (2004) Make, buy or share. WIRTSCHAFTSINFORMATIK 46(3):204-212
Langlois RN (2002) Modularity in technology and organization. Journal of Economic Behavior \& Organization 49(1):19-37

Lee E (2008) Cyber physical systems: design challenges. In: International symposium on object/component/service-oriented real-time distributed computing (ISORC), Orlando, FL, USA

Lyytinen K, Keil T, Fomin V (2008) A framework to build process theories of anticipatory information and communication technology (ICT) standardizing. International Journal of IT Standards and Standardization Research 6(1):543-573

Marakas G, Hornik S (1996) Passive resistance misuse: overt support and covert recalcitrance in is implementation. European Journal of Information Systems 5(3):208219

March ST, Smith GF (1995) Design and natural science research on information technology. Decision Support Systems 15(4):251266

Mayntz R (2011) Emergenz in Philosophie und Sozialtheorie. In: Greve J, Schnabel A (eds) Zur Analyse und Erklärung komplexer Strukturen. Suhrkamp, Berlin, pp 156-186

Melão N, Pidd M (2000) A conceptual framework for understanding business processes and business process modelling. Information Systems Journal 10(2):105-129

Meredith J (1993) Theory building through conceptual methods. International Journa of Operations \& Production Management 13(5):3-11

Mora M, Gelman O, Paradice D, Cervantes F (2008) The case for conceptual research in information systems. In: International conference on information resources management (CONF-IRM-2008), paper 52

Morgan G (1997) Images of organization, 2nd edn. Sage, Thousand Oaks

Nagasundaram M, Bostrom R (1994) The structuring of creative processes using GSS: a framework for research. Journal of Management Information Systems 11(3):87114

Nandhakumar J, Rossi M, Talvinen J (2005) The dynamics of contextual forces of ERP implementation. The Journal of Strategic Information Systems 14(2):221-242

Nelson R, Winter S (1982) An evolutionary theory of economic change. Belknap Press/Harvard University Press, Cambridge

Newell S, Swan JA, Galliers RD (2000) A knowledge-focused perspective on the diffusion and adoption of complex information technologies: the BPR example. Information Systems Journal 10(3):239-259

Norman DA (2004) Affordance, conventions, and design. Interactions 6(3):38-43

Orlikowski WJ (1992) The duality of technology: rethinking the concept of technology in organizations. Organization Science 3(3):398-427

Orlikowski WJ (2000) Using technology and constituting structures: a practice lens for studying technology in organizations. Organization Science 11(4):404-428

Pentland BT, Feldman MS (2008) Designing routines: on the folly of designing artifacts, while hoping for patterns of action. Information and Organization 18(4):235-250

Pentland BT, Haeram T, Hillison DW (2009) Using workflow data to explore the structure of an organizational routine. In: Becker MC Lazaric N (eds) Organizational routines: advancing empirical research. Edward Elgar, Cheltenham, pp 47-67

Poole MS, DeSanctis G (2004) Structuration theory in information systems research methods and controversies. In: Whitman
M, Woszcynski A (eds) Handbook of information systems research. Idea Group Glos, Hershey, pp 206-249

Richter A, Riemer K (2013) Nutzungsoffene Anwendungssoftware. WIRTSCHAFTSINFORMATIK 55(3):193-196

Riemer K, Filius S (2008) Kontextualisierung der Medienwahl mit Hilfe von Kommunikationsgenres. WIRTSCHAFTSINFORMATIK 51(2):192-205

Rosemann M, Andersson M, Lind M (2011) Digital complementary assets. In: 32 nd International conference on information systems, Shanghai, China, pp 1-16

Rosenkranz C (2011) Information systems development as a social process: a structurational model. In: 32th International conference on information systems, Shanghai, China

Sanchez R, Mahoney JT (1996) Modularity, flexibility, and knowledge management in product and organization design. Management 17(Winter special issue):63-76

Saravanamuthu K (2002) Information technology and ideology. Journal of Information Technology 17(2):79-87

Sarker S, Sarker S, Sidorova A (2006) Understanding business process change failure: an actor-network perspective. Journal of Management Information Systems 23(1):51-86

Schäfermeyer M, Rosenkranz C, Holten R (2012) Der Einfluss der Komplexität auf die Standardisierung von Geschäftsprozessen. WIRTSCHAFTSINFORMATIK 54(5):251-261

Sein MK, Henfridsson O, Purao S, Rossi M, Lindgren R (2011) Action design research. Management Information Systems Quarterly 35(1):37-56

Selander L, Henfridsson O (2012) Cynicism as user resistance in IT implementation. Information Systems Journal 22(4):289-312

Shaw DR, Holland CP (2010) Strategy, networks and systems in the global translation services market. The Journal of Strategic Information Systems 19(4):242-256

Song M, van der Aalst WMP (2008) Towards comprehensive support for organizational mining. Decision Support Systems 46(1):300-317

Srivardhana T, Pawlowski S (2007) ERP systems as an enabler of sustained business process innovation: a knowledge-based view. The Journal of Strategic Information Systems 16(1):51-69

Teubner R (2013) Informationssystem-Strategie. WIRTSCHAFTSINFORMATIK 55(4): 239-255

Van der Aalst W (2011) Process mining: discovery, conformance and enhancement of business processes. Springer, Heidelberg

Van der Aalst W, Weijters A (2004) Process mining: a research agenda. Computers in Industry 53(3):231-244

Van der Aalst W, van Dongen B, Herbst J, Maruster L, Schimm G, Weijters A (2003) Workflow mining: a survey of issues and approaches. Data \& Knowledge Engineering 47(2):237-267

Vargo SL, Lusch RF (2004) Evolving to a new dominant logic for marketing. Journal of Marketing 68(1):1-17

Vom Brocke J, Rosemann M (2010a) Foreword. In: vom Brocke J, Rosemann M (eds) Handbook on business process management, vol. 1. Introduction, methods, and information systems. Springer, Heidelberg. pp V-IX

Vom Brocke J, Rosemann M (eds) (2010b) Handbook on business process manage- 
ment, vol. 1. Introduction, methods, and information systems. Springer, Heidelberg

Vom Brocke J, Rosemann M (eds) (2010c) Handbook on business process management, vol. 2. Strategic alignment, governance, people and culture. Springer, Heidelberg

Wang ETG, Tai JCF, Grover V (2013) Examining the relational benefits of improved interfirm information processing capability in buyer-supplier dyads. Management Information Systems Quarterly 37(1):149-173

Weick KE (1976) Educational organizations as loosely coupled systems. Administrative Science Quarterly 21(1):1-19

Willcocks L, Smith G (1995) IT-enabled business process reengineering: organizational and human resource dimensions. The Journal of Strategic Information Systems 4(3):279-301
Winter R (2008) Design science research in Europe. European Journal of Information Systems 17(5):470-475

Wittmann T, Bruckner T (2007) Agentenbasierte Modellierung urbaner Energiesysteme. WIRTSCHAFTSINFORMATIK 49(5):352360

Yu E (2001) Agent orientation as a modelling paradigm. WIRTSCHAFTSINFORMATIK 43(2):123-132 